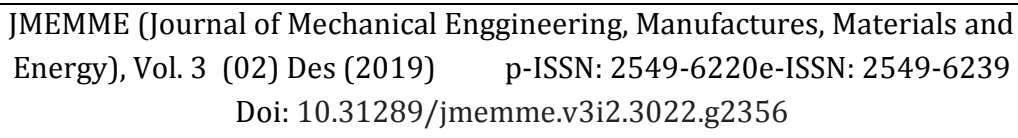

\title{
DESIGN AND MANUFACTURE OF SKATEBOARD FROM BANANA STEM
}

\author{
Achmad Jusuf Zulfikar*, Bobby Umroh, M. Yusuf R. Siahaan \\ Program Studi Teknik Mesin, Universitas Medan Area \\ Diterima: 28-10-2019 ; Disetujui: 24-11-2019 ; Diterbitkan: 30-12-2019 \\ *Corresponding author: zulfikar@staff.uma.ac.id
}

\begin{abstract}
A skateboard is a small piece of wood shaped like a surfboard with four wheels attached to it that is used to glide on a certain track. In general, this tool is made using wood material taken from nature and vulnerable to environmental damage issues. In this research, the waste of banana stems will be processed into the main raw material for skateboarding. The type of material chosen is the type of composite material with banana stem waste selected as reinforcement and polyester resin as the matrix material. The purpose of this research is to design and manufacture a skateboard made of composite fiber reinforced banana stem fibers and to test its flexural strength to obtain the characteristics of the material formed. The design was carried out with the help of the 2007 version of Autocad software by following commercial skateboard standards. Flexural testing was carried out at the Impact and Fracture Research Center laboratory, Faculty of Engineering, University of North Sumatra. Static static testing of polymer composite board specimens from banana stems obtained the average value data for the composition of 5\% banana stems is $9.81 \mathrm{MPa}$, for the composition of $10 \%$ banana stems an average of $13.60 \mathrm{MPa}$, and composition of $15 \%$ banana stems the average is $27.20 \mathrm{MPa}$. 2. The analysis shows that the best composition is $15 \%$ of banana stems, with an average flexural strength value of $27.20 \mathrm{MPa}$. Therefore, the composition used in this study is the composition of $15 \%$ reinforcement of banana stems.
\end{abstract}

Keywords: Skateboard, Banana Stem, Composite, Flexural Strength

How to Cite: Zulfikar, A.J., 2019, Design And Manufacture of Skateboard From Banana Stem. JMEMME (Journal of Mechanical Enggineering, Manufactures, Materials and Energy), 3(02): 109-116 


\section{INTRODUCTION}

In general, banana stems after harvest are only considered as waste and left to rot naturally in the soil or used as fertilizer for certain plants. Based on the research results, the available raw material of banana stems is abundant with the amount of banana tree production per year can reach up to 50 million metric tons[1]. At this time, this plant is only used for conventional products, such as ropes[2], threads, mats, handbags, and wallets[3].

A skateboard is a small piece of wood shaped as a surfboard with four wheels attached to it that is used to glide on a certain track, such as a highway, a path, etc. In general, this tool is made using wood material taken from nature and vulnerable to environmental damage issues. Margono et al [4] have conducted an investigation into the amount of forest loss in the territory of the Republic of Indonesia for 12 years, ie from 2000 to 2012. Based on the results of the study, in that period there was a loss of forest both caused by changes in forest function, harvesting results forests, forest encroachment, etc., averaging up to 54000 ha per year (fig. 1). Thus we need an innovation activity in the material field to find a solution to the problem.

In this research, the waste of banana stems will be processed into the main raw material for making skateboard boards. The type of material chosen is the type of composite material with banana stem waste selected as reinforcement and polyester resin as the matrix material. Fundamentally, a composite material is a material which is a combination of matrix and reinforcement. This material has a characteristic that is even though it has formed a new material, but the characteristics of the constituent materials are still visible and dominating. The choice of material is due to the easy manufacturing process and the relatively lower production costs compared to other types of manufacturing, such as metals, ceramics, etc.

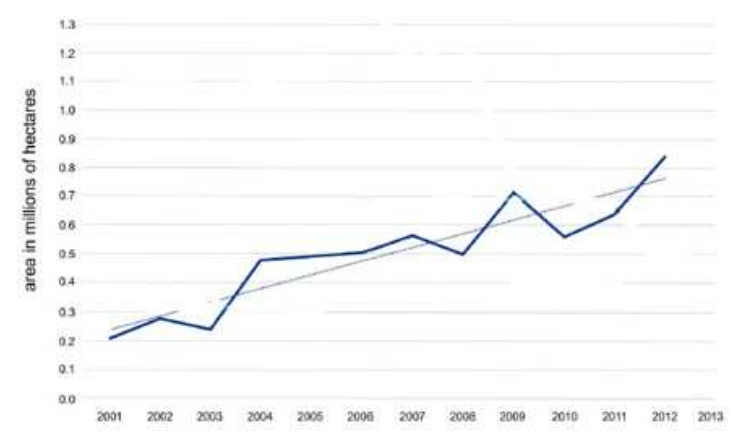

Fig. 1. Chart of forest loss in Indonesia in the period 2000-2012

The need for skateboards that are designed from natural materials is one form of innovation in the development of engineering materials. Banana stems can be used as reinforcement in composite materials to improve their mechanical properties. Natural fiber reinforced composites are widely applied to devices that require materials that have a combination of two basic properties, which are strong but also lightweight, so it is expected to produce products that are lighter, corrosion resistant, waterproof, attractive performance, environmentally friendly and less machining processes. Banana stem fiber has these requirements so it is very potential if it is used as the main raw material to replace natural wood. 
Utilization of banana stems in the manufacture of this tool can reduce the selling price of the tool because it has abundant raw materials and is very cheap. However, if it has been used to make this tool with a high selling price, then economically, this will provide additional income for banana farmers in general.

The development of the industrial world today requires environmentally friendly materials for manufacturing a product. Industries have begun to reduce the use of metal materials in various components due to the weight of the components produced, the formation process is relatively difficult, undergoes a corrosion process and the production costs are relatively expensive. Therefore, many other materials have been developed which have characteristics that are close to the desired metal material characteristics. One material that has been developed today is natural fiber reinforced composites.

Skateboard consists of three main components, namely: deck, truck, and wheels [5]. Deck is a board that is used for operators resting while playing skateboard. This section must be strong enough to withstand the weight of the operator's body. In addition, this part must also be lightweight so that it is easy for the operator to maneuver. The size of this section on average has a length of 32 inches $(81.3 \mathrm{~cm})$, width of 8 inches $(20.3$ $\mathrm{cm})$, and a thickness of approximately 0.5 inches $(1.3 \mathrm{~cm})$. The construction of this section is bent at the front and rear so that the operator's feet are able to stand. The second part is the truck, which is the component used to hold the wheels. This part is usually made of metal so it is firmly gripping the wheel. The third part is the wheel that functions as a part that causes the skateboard to glide on the runway.

Banana trees (musa spp) are fruit plants originating from the Southeast Asian region which then spread to Africa (Madagascar), and South and Central America [6]. In West Java, bananas are called cau while in Central Java and East Java they are called Gedang. These plant products in the form of bananas that can be consumed directly by humans. This plant waste in the form of banana stems are generally only used for fertilizer and animal feed. Utilization of technology products is still very little and needs further research. A. Pappu et al. [7] have conducted research on the possibility of using banana fiber as a reinforcement for epoxy composite materials. The result is obtained a fairly good increase in the tensile strength of composite materials, which reaches 250-450 MPa. S.M. Sapuan et al [8] have conducted studies on the tensile and flexural strength of banana fibers formed in three different sizes. The result was that there was no significant change between the three specimen sizes and the potential to be developed into commercial products. Zulfikar et al [9] have conducted a study of the possibility of using porous materials to produce new types of composite materials. The result is obtained a hollow composite material called Polymeric foam (PF) which is able to reduce the load properly. 
The matrix in the composite functions as a fiber binding material into a structural unit that serves to protect from material damage externally and forwards or moves the external load experienced to the shear plane between the fiber and the matrix [10]. Polymer matrices that are often used for composites consist of two types, namely thermoplastics and thermosets [11].

A good composite must be able to absorb the energy given to the matrix and spread it throughout the composite components [12]. In addition composites with fiber reinforcement must have the ability to withstand high stresses so that the fiber and the matrix can interact with each other and finally the stress distribution takes place. This capability should ideally be owned by the matrix and fiber. The strength of the bond between the fiber and the matrix is influenced by voids [13], namely the presence of gaps in the fiber or imperfect shape of the fibers which can cause the matrix to not be able to fill the empty space in the mold. If the composite receives a load, then the stress area will move to the void region so that it will reduce the strength of the composite.

The purpose of this research is to design and manufacture a skateboard made of composite fiber reinforced banana stem fibers and to test its flexural strength to obtain the characteristics of the material formed.

\section{METHODE}

This research was carried out at the Laboratory of Medan Area Manufacturing Process for three months. The design was carried out with the help of the 2007 version of Autocad software by following commercial skateboard standards (Fig. 2).

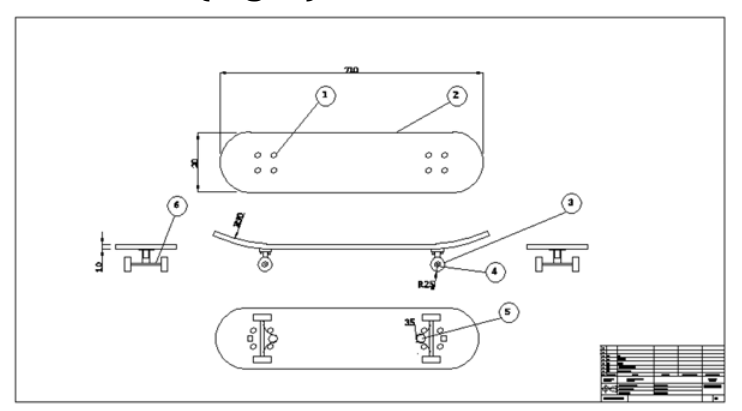

Fig. 2. Skateboard technical drawing

The sheets of banana stems that are still wet are first cut into pieces with a length of $800 \mathrm{~mm}$ and a width of $150 \mathrm{~mm}$. After that weighed approximately 500 grams in wet conditions and dried in the sun to a moisture content below $5 \%$.

The matrix used is a type of unsaturated Polyester Resin with the trademark BTQN 157 EX with the addition of catalyst material which serves as an accelerating process for hardening the matrix. For ease in the process of dismantling, wax material is used. This material serves as a separating medium between specimens and molds. This material will facilitate the separation of specimens during the disassembly process so that the specimen is not sticky on the surface of the mold. Plasticine serves to assist the formation of skateboard boards in mold. Talk flour functions as a surface smoothener on the printed output. 
The procedure for original model skateboard board design is as follows: a) measurement of original model skateboard dimensions, b) making technical drawings of skateboard board mold design, c) making molds according to designs that have been made, and $\mathrm{d}$ ) revisions as needed if needed after making process. The procedure of making molds in this study are as follows: a) prepare the tools and materials needed, b) measure the pattern on the mold that will be made in accordance with its original shape, c) cut the pattern that has been made using a cutting machine, $d$ ) unite between parts using a welding transformer, e) smooth the surface of the mold using a grinder with sandpaper eyes, and f) Paint the molds on the top and bottom of the mold.

Flexural testing was carried out at the Impact and Fracture Research Center laboratory, Faculty of Engineering, University of North Sumatra. This test uses the UTM Shimadzu Servopulser 10 $\mathrm{kN}$ test tool (Fig. 3). Test specimens were formed following a three-point flexural test standard with a length of $200 \mathrm{~mm}$, a thickness of $20 \mathrm{~mm}$ and a height of 20 $\mathrm{mm}$ (Fig. 4).

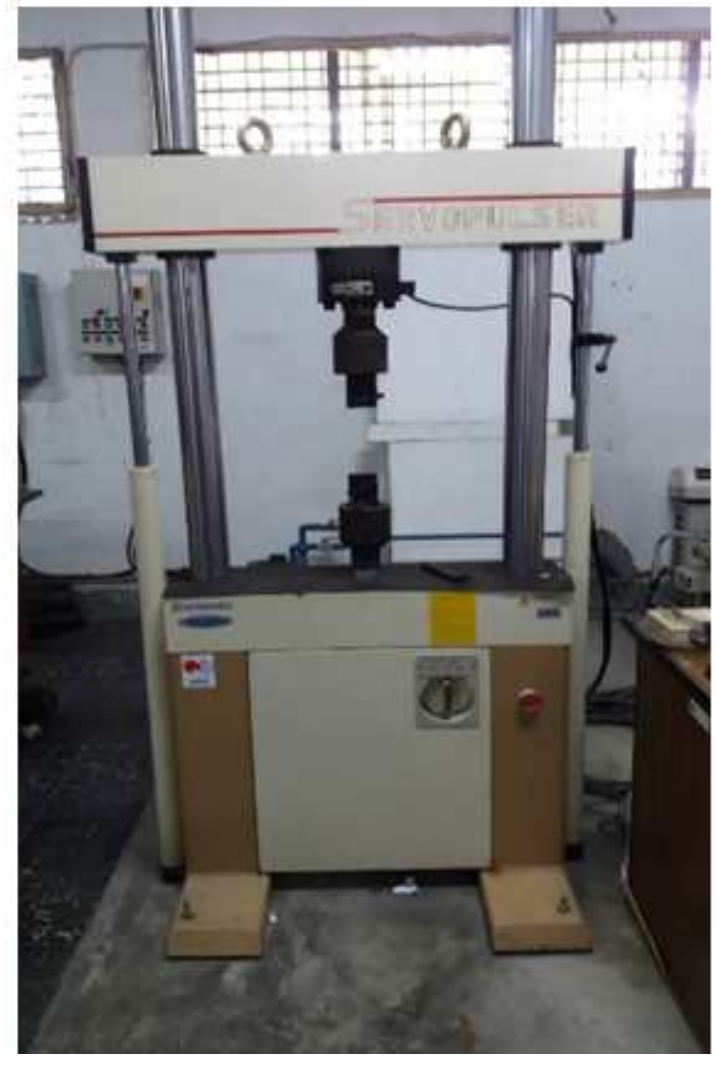

Fig. 3. Universal Testing Machine (UTM) Shimadzu Servopulser $10 \mathrm{kN}$

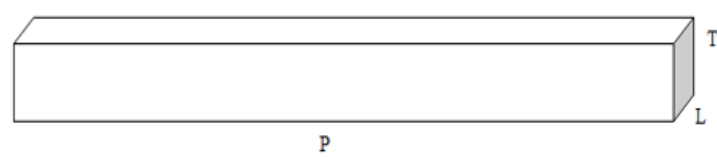

Fig. 4. Dimension on specimen: $\mathrm{P}=200 \mathrm{~mm}, \mathrm{~L}=$ $20 \mathrm{~mm}$, and $\mathrm{T}=20 \mathrm{~mm}$

The testing carried out is flexural testing and the testing procedure is as follows: (1) preparation of tools and materials, (2) prepare the test rig needed for flexural testing, (3) Turn on the selvupulser machine, (4) connect the device to the Laptop via a USB cable for data collection, (5) place the specimen on the test rig and arrange it so that the center of the specimen is precisely about the penetrator, (6) the testing and data collection process. 
Zulfikar, A.J., Design And Manufacture of Skateboard From Banana Stem

\section{RESULT AND DISCUSSION}

The shape of the skateboard mold that has been designed and made to fit the standard commercial size is shown in Figure 5.

a).

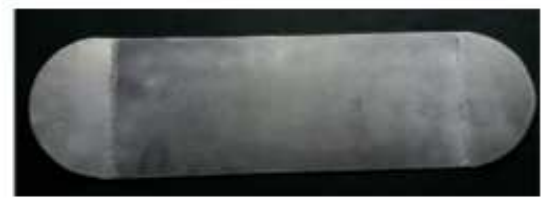

b).

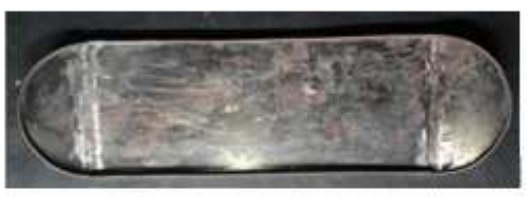

Fig. 5. Skateboard mold on commercial standar:

(a) top cover, and (b) base

The graph of the flexural test results of the polymer composite board specimens reinforced with banana chips based on their reinforcement composition is shown in Figure 6 to 8.

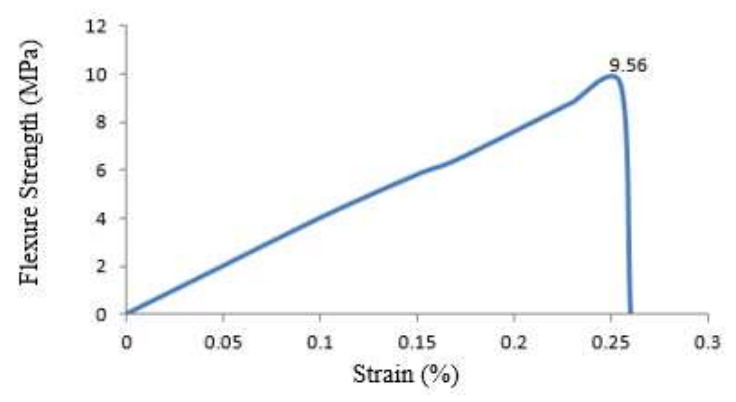

Fig. 6. Graph of flexural test results of polymer composite materials reinforced by $5 \%$ banana stems

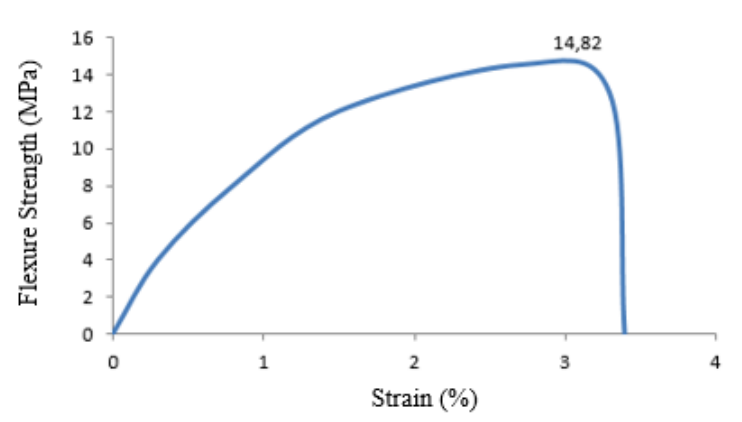

Fig. 7. Graph of flexural test results of polymer composite materials reinforced by $10 \%$ banana stems

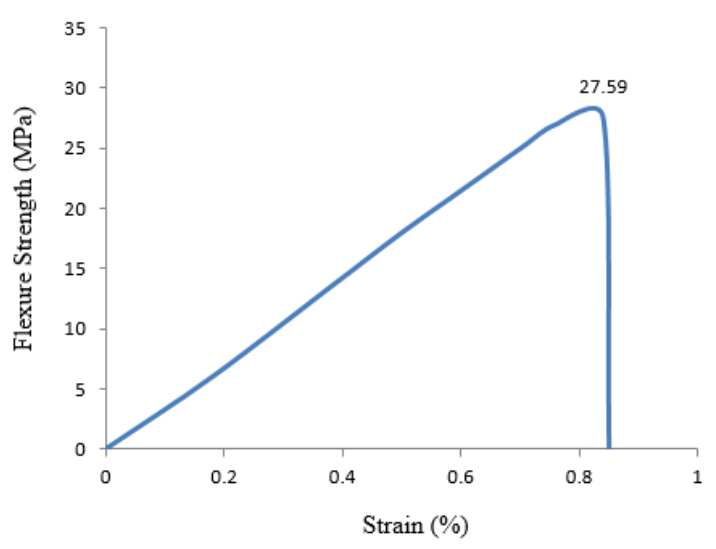

Fig. 8. Graph of flexural test results of polymer composite materials reinforced by $15 \%$ banana stems

The values of the test results are shown in Table 1 and Figure 9 to obtain the average value of the flexural strength of the board.

Table 1. Graph of the results of flexure testing on specimens

\begin{tabular}{ccccc}
\hline \multirow{2}{*}{$\begin{array}{c}\text { Composition } \\
(\%)\end{array}$} & \multicolumn{4}{c}{ Flexure Strength $(\mathrm{MPa})$} \\
\cline { 2 - 5 } & Test 1 & Test 2 & Test 3 & Average \\
\hline 5 & 9,96 & 9,92 & 9,56 & 9,81 \\
10 & 14,82 & 14,82 & 11,16 & 13,60 \\
15 & 27,88 & 26,14 & 27,6 & 27,20 \\
\hline
\end{tabular}

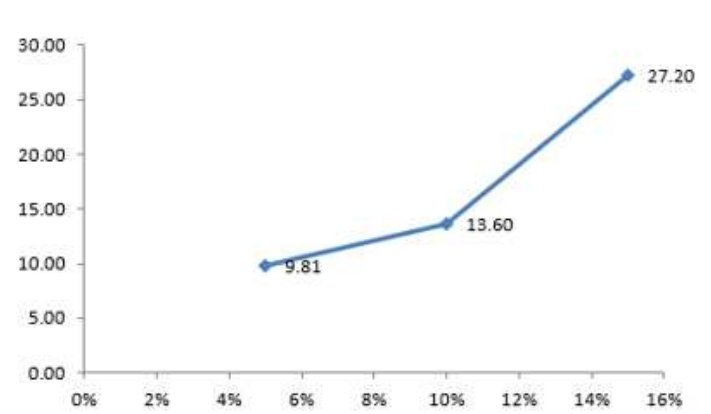

Fig. 9. Graph of average value of flexural strength of composite boards reinforced with banana stems

Based on the average graph shown in Figure 9, the best composition of composite board specimens is reinforced 
by banana stems due to the flexural load found in the composition of $15 \%$ of conch shell powder content. The average flexural strength of specimens in this composition is $27.20 \mathrm{MPa}$. It appears that the composition of the $15 \%$ banana stem content has a higher value compared to the composition of $5 \%$ and $10 \%$.

The results of the flexural specimen testing of polymer composite boards were strengthened by bananas. The results of the composite flexural testing are seen in Figure 6 to 8 above the best average value in the testing of composite bending specimens is $27.20 \mathrm{MPa}$ the best composition in the composite bending test is $15 \%$, it appears that the composition of $15 \%$ has the highest stress compared to the composition of $5 \%$ and $10 \%$.

\section{CONCLUSION}

Based on the results of the study obtained a skateboard board made of composite banana rods with size and shape adjusting to the size and shape of the commercial. The mold is made of stainless steel (stainless steel) and uses a binder structure during the printing process. Static static testing of polymer composite board specimens from banana stems obtained the average value data for the composition of $5 \%$ banana stems is $9.81 \mathrm{MPa}$, for the composition of $10 \%$ banana stems an average of $13.60 \mathrm{MPa}$, and composition of $15 \%$ banana stems the average is $27.20 \mathrm{MPa}$. The analysis shows that the best composition is $15 \%$ of banana stems, with an average flexural strength value of 27.20 MPa. Therefore, the composition used in this study is the composition of $15 \%$ reinforcement of banana stems.

\section{ACKNOWLEDGMENT}

High appreciation for the Head of Manufacturing Process Laboratory, University of Medan Area, namely Mr. Bobby Umroh, Which has provided facilities during this research activity. The award was also given to the Coordinator of the Impact and Fracture Research Center, University of North Sumatra, Mr. Nuzuli Fitriadi, who assisted in the static testing of the composite material with reinforced banana stems.

\section{REFERENCES}

[1] H. Cheung, M. Ho, K. Lau, F. Cardona, and D. Hui, "Natural fibre-reinforced composites for bioengineering and environmental engineering applications," Compos. Part B, vol. 40, no. 7, pp. 655663, 2015.

[2] C. Vigneswaran, V. Pavithra, V. Gayathri, and K. Mythili, "Banana Fiber: Scope and Value Addes Product Development," J. Text. Apparel, Tecnol. Manag., vol. 9, no. 2, pp. 1-7, 2015.

[3] N. VENKATESHWARAN and A. ELAYAPERUMAL, "Banana Fiber Reinforced Polymer Composites A Review," J. Reinf. Plast. Compos., vol. 29, no. 15, 2014.

[4] B. A. Margono, P. V Potapov, S. Turubanova, F. Stolle, and M. C. Hansen, "Primary forest cover loss in Indonesia over 2000 - 2012," pp. 1-5, 2017.

[5] D. Kurniasih, "ANALISIS PERANCANGAN SKATEBOARD DENGAN QUALITY FUNCTION DEPLOYMENT - HOUSE OF QUALITY," Spektrum Ind., vol. 11, no. 1, pp. 117-242, 2013. 
[6] J. C. Mejía, B. R. Rodríguez, and J. J. Olaya, "The influence of alkali treatment on banana fibre 's mechanical properties," Ing. E Investig., vol. 32, no. 1, pp. 83-87, 2015 .

[7] A. Pappu, V. Patil, S. Jain, A. Mahindrakar, and R. Haque, "Advances in industrial prospective of cellulosic macromolecules enriched banana biofibre resources: A review," Int. J. Biol. Macromol., vol. 79, pp. 449-458, 2015.

[8] S. M. Sapuan, "Materials \& Design Mechanical properties of woven banana fibre reinforced epoxy composites," vol. 27, pp. 689-693, 2016.

[9] A. J. Zulfikar, B. Umroh, and M. Y. R. Siahaan, "Investigation of Mechanical Behavior of Polymeric Foam Materials Reinforced by Oil Palm Empty Fruit Bunches (OPEFB) Fibers Due to Static and Dynamic Loads," J. Mech. Enggineering, Manuf. Mater. Energy, vol. 3, no. o1, pp. 10-19, 2019.

[10] Zulfikar and Misdawati, "Manufacture of mold of polymeric composite water pipe reinforced charcoal Manufacture of mold of polymeric composite water pipe reinforced charcoal," in Manufacture of mold of polymeric composite water pipe reinforced charcoal, 2018, pp. 3-8.

[11] C. Corvette, "Introduction to composite materials 1.1," pp. 1-16, 2015.

[12] K. Lau, P. Hung, M. Zhu, and D. Hui, "Properties of natural fibre composites for structural engineering applications," Compos. Part B, vol. 136, no. October 2017, pp. 222-233, 2018.

[13] L. Mohammed, M. N. M. Ansari, G. Pua, M. Jawaid, and M. S. Islam, "A Review on Natural Fiber Reinforced Polymer Composite and Its Applications," Int. J. Polym. Sci., vol. 2015, 2015. 